\title{
Rh ISOIMMUNIZATION: A REVIEW
}

\author{
by Hossam E. Fadel, M.L. \\ Associate Prolessor Obstetrics. Gynecology; \\ Chief Maternal-Fetal Medicine Section; Director of Fellowship \\ Program in Maternal-Fetal Medicine \\ Medical College of Georgia, Augusta. Georgia
}

$\mathrm{Rh}$ isoimonunization is the most common cause of hemolytic disease of the newborn (erythroblastosis retalis). The introduction of Rho (D) immune globulin (Rhogam) prophylaxis for clinical use in 1968 has resulted in a marked decrease in the incidence of hemolytic disease of the newborn.' The number of affected newborns in the U.S.A. dropped from an estimated 16,000 in 1979 to 6.000 in 1975. Infant mortality due to R h hemolytic discase decreased from 2.7/10.000 live births in $1968109.9 / 10,000$ live births in 1975.?

It was hoped that this disease would be completely eliminated but unfortunately it was not. Obstetricians still encounter and have to manage $R h$ sensitized women albeit in decreasing numbers. To continue this decreasing trend obstetricians have to maintain vigilance in identifying these unfortunate women, and to manage them properly utilizing the newly acquired concepts and techniques. Meanwhile, attempts should continue to improve on the already excellent $\mathrm{Rh}$ prophylaxis program. In this article I shall review some basic concepts about the pathology, and incidence of this disease, and discuss its diagnosis and management with particular emphasis on the use of ultrasonography as well as the role of plasmapheresis in its management.

\section{Pathology}

The "Rh antigen" was first discovered in 1940, only to be later recognized to consist of multiple antigens, designated D, d. C, c E, e. These have varied antigenic potency. The $\mathrm{D}$ antigen is about 30 times more antigenic than $c$, and $E$ antigens, whereas, $C$ and $e$ antigens are very weak antigens. The $D$ antigen is less antigenic than $\mathrm{A}$ and $\mathrm{B}$ blood group antigens. $\mathrm{Rh}$ antigens are inherited according to simple Mendelian laws, with various possible combinations of the alleles on these 3 loci. By common parlance $\mathrm{Rh}$ positivity is related to the presence of the " $D$ " allele. "The $R h$ positive person can be heterozygous i.e. Dd or homozygous DD.'4

Erythroblastosis fetalis results from incompatible pregnancies in which the fetus inherits the $D$ antigen from the father while the mother lacks this antigen. Fetomaternal bleeds i.e. fetal cells crossing the placental "barrier" into the maternal circulation, stimulate the maternal immune system to produce $\mathrm{Rh}$ (D) antibodies. The formed immunoglobulin $\mathrm{G}(\mathrm{Ig} G)$ antibodies are capable of crossing the placenta into the fetal circulation causing fetal hemolysis. In mild cases mild hemolytic anemia results. In more severe cases. the hemolysis is so rapid that the neonate develops hemolytic jaundice and severe ancmia (Icterus gravis neonatorum). In the most severe cases the a nemia - in utero - is so severe that the fetus develops a combination of heare failure. liver failure, hypoalbumina that result in the characteristic disorder "hydrops fetalis". This is characterized by markcd generalized edema, pleural effusions, ascites. hepatosplenomegaly. These fetuses are at a very high risk of intrauterine fetal and neonatal death. ${ }^{3}{ }^{4}$

\section{Incidence}

The incidence of $\mathrm{Rh}$ incompatible pregnancies i.e. $\mathrm{R} h$ negative wife and $\mathrm{R} h$ positive husband is estimated to be $10 \%$ in Caucasians. $5 \%$ in Blacks. $1 \%$ in Orientals and $30 \%$ Baskes (Spain). The probability of maternal $\mathrm{Rh}$ isoimmunization by a single incompatible pregnancy and delivery is $17 \%$. If there is associated ABO incompatibility i.e. blood group A or B fetus in group $\mathrm{O}$ mother, the risk of immunization is reduced to $8 \%$. This is due to the rapid hemolysis of fetal red cells as they enter the maternal circulation reducing the chances of the matcrnal immune system to recognize the $R h$ antigen. $R h$ isoimmunization can also occur after termination of early pregnancy whether spontancous or induced abortion or ectopic pregnancy. It is estimated that as little as $0.1 \mathrm{ml}$ of $\mathrm{Rh}$ positive blood can initiate the process of isoimmunization. However, the risk is relatively small i.e. $2-3 \%$ of incomparible pregnancies. $\mathrm{Rh}$ isoimmunization also result from misnatched blood transfusion at any lime. It has been found that transfusion of $500 \mathrm{ml}$ of $\mathrm{Rh}$ positive blood resulted in immunization of $80 \%$ of $\mathrm{Rh}$ negative individuals. Although it is commonly known that $\mathrm{Rh}$ isoimmunization occurs at the time of delivery, it is less known that isoimmunization occurs, as well, during pregnancy. The risk of immunization during first pregnancy (or within 3 days of delivery) is $0.7-$ $2.0 \%$. Factors predisposing 10 isoimmunization during pregnancy (i.e. fetomaternal bleeding) include: amniocentesis, external verison, placenta previa or abruption.s

Rh immunoglobulin (Rhogam) prophylaxis became clinically available in 1968. This followed years of basic research and clinical irials.' The basis for such prophylaxis is that active immunization is suppressed by the presence of passive antibody to the antigen. Rh antibody administered to the mother 
blocks or binds $\mathrm{Rh}$ antigenic determinants on the fetal red cells that may enter the maternal circulation preventing their contact with the surface receptors of her potential immunocytes.' Rhogam to be effective has to be administered within 72 hours of delivery (or the first lime of fetomaternal bleed). in adequatc dose (the standard dose is $300 \mathrm{ug}$ ). and before aclive immunizalion has begun. ${ }^{\prime}$ "

The incidence of $R$ h sensitization has dramatically decreased as a result of the widespread use of Rhogam prophylaxis, but it has not been climinated.'." This is due partly at least to under utilization. It has been estimated that Rhogam was administered to only 80 $82 \%$ of eligible patients during the years 1974-1976.' A significant component of this underutilization relates to early termination of pregnancies when Rh typing. antibody screening and cvaluation for Rlogam prophylaxis is major fetomaternal bleeds. It has been determined that each $30 \mathrm{ug}$ of Rhogam is capable of effectively blocking sensitization caused by $1.5 \mathrm{ml}$ of red cells. If the letomaternal bleeding is $15 \mathrm{ml}$ red cells $(>30 \mathrm{ml}$ of fetal blood) the standard dose (300 ug) will fail to prevent sensitization. Ideally. all parturients should have a Kleihauer-Betke test on a peripheral smear whereby the number of fetal cells in the maternal circulation is counted. the volume of the bleed determined and the dose of Rhogam increased proportionately. If this is not leasible, it might be considered. at least, in cases where there is increased incidence of "large" felomaternal bleeds e.g. cesarean section. manual removal of the placenta, placenta previa or abruption.

Obviously, sensitization during pregnancy cannot be prevented by the current prophylaxis regimen i.e. where Rhogam is given only postpartum. In order to decrease this risk it is generally recommended that Rhogam be given after amniocentesiss for other operative intervention during pregnancy e.g. external version) if the patient is $\mathrm{Rh}$ negative and unsensitized. Furthermore, all amniocenteses should be performed with ultrasonic guidance to avoid the placenta and minimize the chances (or the amount) of letomaternal bleeding.

However. sensitization has occured in pregnancies in which none of these procedures was performed. Therefore there is growing enthusiasm for routine antenalal $\mathrm{Rh}$ prophylaxis. The Canadian experience has been very promising. Rhogam is administered to all $\mathrm{Rh}$ negative unsensitized women at 28 weeks and then repeated after delivery in only those who deliver $\mathrm{R}$ h positive fetuses. Using this routine. the incidence of Rh sensitization was reduced to $0.1 \%$. The leasibility and cost effectiveness of this regimen is still being studied in the U.S.A., and has yet to be approved by FDA.

\section{Diagnosis and Management of Rh Sensitized Pregnancies}

Blood grouping, Rh typing, and antibody screening should be routine in all prenatal patients (including primigravidae and regardless of the husband blood type). Antibody screening should be repealed in all $\mathrm{Rh}$ negative unsensitized women at 28,32 and 36 weeks. In patients with $\mathrm{Rh}$ antibodies. the titer should be measured.

Evaluation of the fetal involvement is based primarily on the degree of absorbance (optical density; $\Delta O D)$ by the amniotic lluid - obtained by amniocentesis - at wavelength of 450 nanometers. In addition to $\triangle O D$ determination. we utilize the ultrasonic findings 10 detect early signs of severe disease. Untortunately there are no recognizable ultrasonic features of mild disease. The earliest signs are thickening and enlargement of the placenta, and increase in the volume of amniotic fluid (polylydramnios). Subsequently, subcutaneous edema may be manifested around the skull (halo) and later ascitic fluid starts to accumulate in the peritoneal cavity. This will show as a sonolucent area within the abdominal cavity with all the viscera lumped into the center. This characteristic finding is diagnostic of fetal hydrops.

Amniocentesis is indicated in all sensitized pregnancies except if the antibody titer is low $(<1: 16)$ and is not rising. The timing of amniocentesis depends on the titer and the obstetric history. Erythroblastosis letalis tends 10 be more severe with cach subsequent pregnancy with an $\mathrm{Rh}$ positive fectus. The more severe the fetal involvement in a previous pregnancy or the higher the antibody titer in the curren pregnancy. the earlier in pregnancy. amniocentesis should be done. For example. if a patient gave a history of stillbirth or of the birth of a hydropic letus, amniocentesis should begin at about 20 weeks. Whereas if none of the previous offspring Has affected or if they werc only mildly affected, i.e. hemolytic anemia. and especially if the titer is not higher than 1:16 amniocentesis could be delayed up to the $28 \mathrm{th}$ week. Amniocentesis should always be done with realtime ultrasound direction to locate an accessible pocket of amniotic fluid without injury to the placenta or fetus. The $\triangle O D$ is plotted on Liley's chart." If it is in zone I (mild) or II (moderate). amniocentesis is repeated in 10-14 days. If $\Delta O D$ lies in upper zone II or zone III amniocentesis has to be repeated in 7 days. In cases where the $\triangle O D$ continues to be in zone 11 , amniocentesis is repeated every two wecks and labor is induced once fetal lung maturity is allained. In cases where $\triangle O D$ drops to low zone II and especially if it drops 10 zone I. intervals between amniocenteses can be prolonged to 3 weeks and induction of labor can be delayed to the 37 th week 
or beyond, when the cervix becomes favorable.

Intrauterine transfusion (IL'T) was first described by Liley in $1963 .{ }^{\circ}$ Group $\mathrm{O}$ Rh negative packed red cells are injected into the fetal abdomen. The original procedure utilized amniography (injection of radioopaque medium into the amniotic cavity 4 hours prior to the procedure) to delineate the fetal bowel, and fluoroscopic control of the passage of the needle. ${ }^{10}$ The radiation exposure was estimated to be 6.6 rads/procedure." In addition. the procedure is associated with maternal as well as fetal risks. A cooperative multicenter study involving 1097 IUT's into 591 fetuses during the years 1963-1966 reported by Queenan (1969) revealed the lollowing: Fetal trauma occured in $5.5 \%$ of IUT's or $10 \%$ of fetuses transfused. Fetal death occured in $86 \%$ of these fet uses within 2 days. Preterm labor occured in $30 \%$ of patients. Serious maternal infections developed in $0.7 \%$ and maternal bleeding in $5 \%$ of these patients. Serum hepatitis occured in $0.3 \%$ of the mothers and $0.7 \%$ of the infants. Out of these fetuses. 203 survived. 300 died in utero and 88 died neonatally for a survival rate of $34 \%$. Better survival rates have been reported in some more recent series ${ }^{11},{ }^{12}$ but not in others. ${ }^{13}$

An important recent development is the utilization of ultrasonic guidance in performling IUT's. Both compound and dynamic scanning have been used with either linear array or sector scan transducers. ${ }^{14} .^{16}$ In our institution we utilize realtime scanning with lineal array transducers. This obviates the need for amniography because fetal bowel. liver and bladder can be identified and the insertion of the needle can be monitored with varying degrees of success with the realtime scan. After the needle is felt (and probably seen) to be in the peritoneal cavity. $3-5 \mathrm{ml}$ of radioopaque dye is injected and a spot $x$-ray obtained to document the intraperitoneal location with the characteristic honeycomb appearance." The red blood cells are then slowly iransfused under vision (realtime scanning). Whether the use of ultrasonography will result in less trauma to the fetus and / or better survival rates remains to be seen.

The criteria for IUT has varied somewhat between different investigators. " In our center we use liley's criteria. If the $\Delta$ OD rises into the IUT zone, the procedure is considered. If the fetus is considered to be severely affected (Liley's Zone III) but close to 32 wecks. maturity studies are performed on the amniotic

\section{REFERENCES}

I. Freda, V.J., Gorman, J.G.. Pollack. W., et al: Prevention of Rh Hemolytic Disease. Ten years. clinical experience with Rh Immunoglobulin. N. Engl. J. Med. 292:1014, 1975.

2. Wysowski, D.K., Flynt, J.W., Goldberg, M.F.. et al: Rh hemolytic disease. Epidemiologic sur- fluid and if mature (L/S ratio $>2$ ) the fetus is delivered rather than subjected to IUT. IUT should be repeated every 2 weeks, until the 32nd week when delivery usually by cesarean section is done.

It has been shown that the survival rates are much less in feluses in whom the initial IUT was performed at $<25$ weeks ( $9 \%$ vs. $34 \%$ for total group). ${ }^{4}$ This is partly due to the greater technical dilliculty in performing the procedure and that these cases represent a more severe degree of the disease. This raised the question of an alternative method of treatment namely plasmapheresis. whereby the maternal plasma is exchanged for plasmanate, saline or fresh frozen plasma without $\mathrm{Rh}$ antibodies. This reduces the antibody concentration and was hoped to decrease the severity of the disease. ${ }^{17}, 18$ We have used this technique in a few patients. In these cases plasmapheresis served to ameliorate the condition of the fetus to allow postponement of the IUT to a later date when it could be done more successfully (beyond 28 w). In one patient. 2 courses ol plasmapheresis 4 days each were performed in consecutive weeks. Total plasma removed during each course was $16.8 \mathrm{~L}$. This was replaced by $3.3 \mathrm{~L}$. fresh frozen plasma and $9.4 \mathrm{~L}$ of plasmanate during the first course, and $7 \mathrm{~L}$. Fresh frozen plasma +5.8 L. of plasmanate during the second course. IUT was performed a few days after the last course. Delivery by cesarean section a week later resulted in a moderately affected baby that required multiple exchange transfusions but that survived without complications. Plasmapheresis is not widely used and some investigators believe that it is not useful in the management of $\mathrm{Rh}$ isoimmunization. ${ }^{17}$. ${ }^{14}$ However, I believe that it has a limited role in selected cases. This view is supported by a recent report. ${ }^{20}$

In conclusion, a small but a steady number of patients with severe $\mathrm{Rh}$ isoimmunization will continue to be seen. These patients require specialized obstetric care the includes, amniocenteses. proper interpretation results of amniotic fuid analysis. ability 10 perform IUT, and the judicious use of plasmapheresis in selected cases. In addition, the availability of ultrasonography, laboratory, blood bank, and neonatal intensive care is an essential element of these patients' care. Because of the limited number of these patients. and the degrec of expertise nceded for their care, they are best managed in tertiary centers.

veillance in the United States.1968-1975, JAMA 242: 1.376, 1979.

3. Corson. S. L.: Management of $\mathrm{Rh}$ sensitization. In "Perintal Medicine. Management of the high risk fetus and neonate". Bolognese. R.J. and Schwarz, R.H. (eds.). The Williams \& Wilkins Co. Baltimore, 1977. pp. 153-171. 
4. Queenan, J.T.: Modern management of the Rh problem. Harper and Row Publisters 2nd Edition, New York, 1977

5. Bowman, J.M.: Suppression of Rh isoimmunization: A Review. Obstet. Gynecol. $52: 285,1978$.

6. Schumacker, G.F.B., Schneider, J.; Coordinators of an invitational symposium "Current problems in prophylactic treatment of $\mathrm{Rh}$ Erythroblastosis". J. Reprod. Meci. 6:67, 1971.

7. Grimes, D.A., Ross, W.C., Hatcher, R.A.: Rh inmunoglobulin urilization after spontaneous and induced abortion. Obstet. Gynccol. 50:261. 1977.

8. Henry. G., Wexler, P., Robinson. A.: Rh immunoglobulin after ammocentesis for genetic diagnosis. Obstet. Gynecol. 48:557, 1976.

9. Liley, A.W.: Liquor Amnii analysis in management of pregnancy complicated by rhesus sensitization. Am. J. Obstel. Gynecol. 82:1359, 1961.

10. Liley, A.W.: Intrauterine transfusion of foetus in haemolytic disease. Br. Med. J. 2:1107, 1963.

II. Hamilton. E.G.: Intrauterine transfusion. Safeguard or Peril. Ostet. Gynecol. 50:255, 1977.

12. Bowman, J.M.: The management of $\mathrm{Rh}$ isoim- munization. Obstet. Gynecol. 52:1, 1978.

13. Palmer, A., Gordon, R.R.: A critical review of intrauterine foetal transfusion. Br. J. Obstet. Gynaecol. 83:688, 1976.

14. Cooperberg, P.L., Carpenter, C.W.: Ultrasound as an aid in intrauterine transfusion. Am. J. Obstet. Gynecol. 128:239, 1977.

15. Acker, D. Frigoletto, F.D., Birnholz. J.C.. et al: Ultrasound facilitated intrauterine transfusion. Am. J. Obstet. Gynecol. 138:1200, 1980.

16. Berkowitz, R.L., Hobbins, J.C.: Intrauterine transfusion utilizing ultrasound. Obstet. Gynecol. 57:33, 1981.

17. Powell, L.C.: Intense Plasmapheresis in the pregnant Rh sensitized woman. Am. J. Obstet. Gynecol. 101:153, 1968.

18. Fraser, 1.D., Bennett, M.O., Bothamby, J.E., et al: Intensive Plasmapheresis in severe $\mathrm{Rh}$ isoimmunization. Lancet 1:6, 1976.

19. Bowman, J.M., Peddle, L.J., Anderson, C.: Plasmapheresis in severe $\mathrm{Rh}$ isoimmunization. Vox Sang. 15:272, 1968.

20. Hauth, J.C., Brekken, A.L., Pollack, W.: Plasmapheresis as an adjunct to management of Rh isoimmunization. Obstet. Gynecol. 57:132. 1981. 